\title{
Hermeneutik und Germanistik
}

\section{Hartmut Bleumer · Stephan Habscheid · Constanze Spieß • Niels Werber}

Angenommen: 7. Dezember 2021 / Online publiziert: 21. Dezember 2021

(C) Der/die Autor(en) 2021

\section{Für Ute Hechtfischer}

Vor einem Jahr hatten wir an dieser Stelle nach der aktuellen Relevanz der Hermeneutik, ihrem Zustand und ihren Aussichten in der Germanistik gefragt. ${ }^{1}$ Dem Diskussionsaufruf der LiLi, dessen Aktualität wir mit einem eigenen Beitrag unterstreichen wollten, ${ }^{2}$ hat nicht nur eine bemerkenswerte Anzahl von Reaktionen hervorgerufen. Die Antworten und Thesen haben vielmehr auch ein ebenso spannungsreiches wie breites Spektrum von Positionen ergeben. So präsentieren die folgenden Aufsätze und Essays nicht nur im Einzelnen Ansätze, Voten und Diagnosen zum Stellenwert der Hermeneutik. Weil sie sich immer wieder auf das Risiko eingelas-

\footnotetext{
1 Vgl. Bleumer, Hartmut/Habscheid, Stephan/Spieß, Constanze/Werber, Niels: »Hermeneutik heute? - Ein Call der Zeitschrift für Literaturwissenschaft und Linguistik zur Krise des Textverstehens«. In: Zeitschrift für Literaturwissenschaft und Linguistik 50 (2021), S. 559-562.

2 Vgl. Bleumer, Hartmut/Habscheid, Stephan/Spieß, Constanze/Werber, Niels: »Bindestrich-Hermeneutiken - Neue Verortungen der Lektüre?« In: Literaturwissenschaft und Linguistik 50 (2021), S. 563-580.
}

Hartmut Bleumer $(\bowtie)$

Seminar für Deutsche Philologie, Georg-August-Universität Göttingen, Göttingen, Deutschland E-Mail: hbleume@gwdg.de

Stephan Habscheid · Niels Werber

Germanistisches Seminar, Universität Siegen, Siegen, Deutschland

Stephan Habscheid

E-Mail: habscheid@germanistik.uni-siegen.de

Niels Werber

E-Mail: werber@germanistik.uni-siegen.de

Constanze Spieß

Institut für Germanistische Sprachwissenschaft, Philipps-Universität Marburg, Marburg, Deutschland E-Mail: constanze.spiess@ uni-marburg.de 
sen haben, die Frage nach dem hermeneutischen Status in der Germanistik zu einer Statusbeschreibung der germanistischen Sprach- und Literaturwissenschaft auszuweiten, ergeben sie in der Summe ein schon rhetorisch aufschlussreiches Ensemble der Fachdiskussionen, das selbst wiederum einer hermeneutischen Betrachtung wert wäre.

Insgesamt perspektivieren oder bestreiten die folgenden Beiträge das hermeneutische Problem schon ihrer jeweiligen fachspezifischen Verortung nach über unterschiedliche Ausgangspunkte: Die Aufsätze und Skizzen stammen aus den Bereichen der Linguistik, germanistischen Mediävistik und neueren deutschen Literaturwissenschaft, der amerikanischen Germanistik, Fachdidaktik, Philosophie und Medienwissenschaft. Sie beleuchten von hier aus insgesamt die Situation in Schule, Studium und Forschungsinstitutionen, stellen aber auch die Möglichkeiten einer traditionellen, am Medium des Buches orientierten Lektürepraxis denen der digitalen Medienpraxis gegenüber. Sie erweitern die Fragestellung einerseits grundsätzlich in Richtung einer historischen Ästhetik, und sie suchen diese andererseits mit Blick auf aktuelle methodische Verfahren wissenschaftlicher Rationalisierung zu spezifizieren. Sie votieren zum einen für die Gewähr einer hermeneutischen Selbstsicherheit, die im traditionell vertieften Denkstil der Germanistik ansetzt und sich letztlich, wie auch einzelne Beiträge selbst praktisch zeigen, im elaborierten Sprachstil des wissenschaftlichen Diskurses auszudrücken vermag. Zum anderen sind die Texte aber auch um scharfe rhetorische Pointierungen nicht verlegen, die nicht zuletzt das topische Krisennarrativ des Calls mit Verve ins Visier nehmen.

Derart indizieren die Beiträge eine Debatte, die hermeneutisch nicht zuletzt gerade dort weiterführt, wo der Selbstwiderspruch der hermeneutischen Krisenrhetorik abgelehnt wird, bzw. gerade dort in souveränen Gesten dem Krisennarrativ widerspricht, wo es argumentativ bestätigt wird. Vor allem aber zeigen sich über diese Widersprüche immer wieder interessante methodische und theoretische Anschlussstellen zwischen den einzelnen Fachteilen der Germanistik. Daher möchten wir den Beiträgerinnen und Beiträgern für ihre Diskussionsbereitschaft danken, mit der sie dieses Heft der $\mathrm{LiLi}$ - in der letzten Ausgabe, mit der die LiLi auf 50 Jahre ihres Erscheinens zurückblicken kann - realisiert haben.

Den Anstoß zu diesem Projekt hat Ute Hechtfischer gegeben. Als langjährige, wissenschaftlich wohlinformierte Lektorin des Metzler-Verlages hat sie die LiLi über viele Jahre betreut und nicht zuletzt auch die thematischen und programmatischen Diskussionen in den Sitzungen der Herausgeberinnen und Herausgebern intellektuell bereichert. Auch die Themenstellung dieses Heftes wäre ohne ihren Impuls nicht entstanden. Auf die freundschaftliche Zusammenarbeit mit Ute Hechtfischer, die den Metzler-Verlag im letzten Jahr in andere Bereiche des Kulturbetriebs verlassen hat, erinnern wir uns gerne. Ihr sei dieses Heft gewidmet.

Funding Open Access funding enabled and organized by Projekt DEAL.

Open Access Dieser Artikel wird unter der Creative Commons Namensnennung 4.0 International Lizenz veröffentlicht, welche die Nutzung, Vervielfältigung, Bearbeitung, Verbreitung und Wiedergabe in jeglichem Medium und Format erlaubt, sofern Sie den/die ursprünglichen Autor(en) und die Quelle ordnungsgemäß nennen, einen Link zur Creative Commons Lizenz beifügen und angeben, ob Änderungen vorgenommen wurden. 
Die in diesem Artikel enthaltenen Bilder und sonstiges Drittmaterial unterliegen ebenfalls der genannten Creative Commons Lizenz, sofern sich aus der Abbildungslegende nichts anderes ergibt. Sofern das betreffende Material nicht unter der genannten Creative Commons Lizenz steht und die betreffende Handlung nicht nach gesetzlichen Vorschriften erlaubt ist, ist für die oben aufgeführten Weiterverwendungen des Materials die Einwilligung des jeweiligen Rechteinhabers einzuholen.

Weitere Details zur Lizenz entnehmen Sie bitte der Lizenzinformation auf http://creativecommons.org/ licenses/by/4.0/deed.de. 